\title{
Comparison of Pipeline Embolization Device Sizing Based on Conventional 2D Measurements and Virtual Simulation Using the Sim\&Size Software: An Agreement Study
}

\author{
(D).M. Ospel, (D) G. Gascou, (D) V. Costalat, DL. Piergallini, DK.A. Blackham, and DD.W. Zumofen
}

\begin{abstract}
BACKGROUND AND PURPOSE: The Sim\&Size software simulates case-specific intraluminal Pipeline Embolization Device behavior, wall apposition, and device length in real-time on the basis of rotational angiography DICOM data. The purpose of this multicenter study was to evaluate whether preimplantation device simulation with the Sim\&Size software results in selection of different device dimensions than manual sizing.
\end{abstract}

MATERIALS AND METHODS: In a multicenter cohort of 74 patients undergoing aneurysm treatment with the Pipeline Embolization Device, we compared apparent optimal device dimensions determined by neurointerventionalists with considerable Pipeline Embolization Device experience based on manual 2D measurements taken from rotational angiography with computed optimal dimensions determined by Sim\&Size experts blinded to the neurointerventionalists' decision. Agreement between manually determined and computed optimal dimensions was evaluated with the Cohen $\kappa$. The significance of the difference was analyzed with the Wilcoxon signed rank test.

RESULTS: The agreement index between manual selection and computed optimal dimensions was low $(\kappa$ for diameter $=0.219 ; \kappa$ for length $=0.149, P<.01$ ). Computed optimal device lengths were significantly shorter (median, 14 versus $16 \mathrm{~mm}, T=402, r=-0.28, P<.01$ ). No significant difference was observed for device diameters.

CONCLUSIONS: Low agreement between manually determined and computed optimal device dimensions is not proof, per se, that virtual simulation performs better than manual selection. Nevertheless, it ultimately reflects the potential for optimization of the device-sizing process, and use of the Sim\&Size software reduces, in particular, device length. Nevertheless, further evaluation is required to clarify the impact of device-dimension modifications on outcome.

ABBREVIATION: PED = Pipeline Embolization Device

$\mathrm{T}$ heoretic flow-diversion concepts for aneurysm treatment were originally formulated in the 1990s. ${ }^{1,2}$ Development of metal alloys and delivery systems, however, lagged behind con-

Received September 27, 2018; accepted after revision January 4, 2019.

From the Diagnostic and Interventional Neuroradiology Section (J.M.O., K.A.B., D.W.Z.), Department of Radiology and Nuclear Medicine, and Department of Neurosurgery (D.W.Z.), University Hospital Basel, University of Basel, Basel, Switzerland; Department of Neuroradiology (G.G., V.C., L.P.), Hôpital Gui de Chauliac, Centre Hospitalier Universitaire de Montpellier, University of Montpellier, Montpellier, France; and Postgraduation School of Radiodiagnostics (L.P.), Università degli Studi di Milano, Milan, Italy.

Preliminary results of this study previously presented as a poster at: Annual Meeting of the Society of Neurointerventional Surgery, July 23-26, 2018; San Francisco, California.

Please address correspondence to Kristine A. Blackham, MD, Department of Radiology and Nuclear Medicine, University Hospital Basel, Petersgraben 4, 4051 Basel, Switzerland; e-mail. kristineann.blackham@usb.ch; @johanna_ospel; @KBlackhamMD

三 Indicates article with supplemental on-line tables.

http://dx.doi.org/10.3174/ajnr.A5973 ceptual thought. The first generation of low-porosity endoluminal reconstruction devices therefore became available only in the following decade. ${ }^{3-5}$ The Pipeline Embolization Device (PED; Covidien, Irvine, California) is a member of this larger family of endovascular tools that became known as "flow diverters." The PED was initially approved in the United States by the FDA in 2011 for endovascular treatment of adults with large or giant wide-neck intracranial aneurysms of the internal carotid artery from the petrous to the superior hypophyseal segment, ${ }^{6}$ but indications for its use have subsequently been expanded to a wide range of aneurysm locations and morphologies. ${ }^{7-12}$

Successful intra-arterial placement of the PED ideally produces immediate changes in regional circulation, redirecting blood flow past the aneurysm into the distal normal vasculature. The resultant intra-aneurysmal stasis promotes thrombosis within the aneurysm, which leads to an angiographic appearance of "cure."13 Actual cure, however, is achieved when subsequent 
"endothelialization" of the device occurs, leading to permanent aneurysm exclusion from the circulation. A challenge that inevitably arises when using braided-design flow diverters such as the PED is their mechanical behavior when constrained and forced to accommodate a diameter mismatch along the covered arterial segment. For instance, proximal and distal landing zones are most often of different diameters, and device placement, therefore, naturally involves "oversizing" at one end of the recipient vessel. Sizing mismatch, however, leads to heterogeneity in metal coverage, which, in turn, determines the ability of the device to modulate flow and to sustain endothelial overgrowth, a key factor in the success of the treatment. ${ }^{14,15}$

Deployment of flow diverters is technically far more challenging than conventional stents used as supports for coiling aneurysms. Also, experience with the PED is still increasing, and device behavior during implantation remains somewhat counterintuitive and, at times, challenging to predict. ${ }^{14,15}$ This behavior results in a comparatively flat learning curve and may well contribute to the occurrence of some of the often devastating periprocedural complications. ${ }^{16}$ It is, therefore, desirable to facilitate and optimize device sizing and device positioning through preimplantation simulation. Computer-based-simulation modeling tools such as the Sim\&Size software (Sim\&Cure; Grabels, France) provide the opportunity to simulate and, hence, to anticipate PED behavior of variable dimensions easily and within seconds. In short, this novel technology aims to standardize the PED-sizing process and ultimately promises to increase the neurointerventionalists' ability to confidently select optimal PED dimensions before implantation.

In this multicenter cohort study of 74 patients who underwent aneurysm treatment with PEDs, we compared the dimensions of devices selected by neurointerventionalists with considerable PED experience based on conventional, manual 2D measurements obtained from rotational angiography with the computed optimal PED dimensions determined by Sim\&Size experts, who were blinded to the neurointerventionalists' choice. The purpose was to evaluate whether virtual preimplantation device simulation with the Sim\&Size software results in selection of different PED dimensions compared with conventional (ie, manual) device sizing.

\section{MATERIALS AND METHODS}

Seventy-four consecutive patients undergoing aneurysm treatment with PEDs between January 2015 and December 2016 in center A (Hôpital Gui de Chauliac, Centre Hospitalier Universitaire de Montpellier, University of Montpellier, Montpellier, France) and between January 2017 and February 2018 in center B (Basel University Hospital, University of Basel, Basel, Switzerland) were included. Ethics committee approval and patient consent were obtained.

\section{Baseline Characteristics}

Baseline characteristics included patient sex and age, as well as aneurysm location and maximal diameter. In addition, we recorded the additional use of embolic material such as coils and whether a single PED or a multi-PED construct was used.

\section{Perioperative Complications and Outcome}

Perioperative complications, such as PED deployment failure, occlusion of inadvertently covered branches, and occurrence of hemorrhagic or ischemic stroke, were recorded. Radiologic outcome, including the presence of residual aneurysm perfusion or an endoleak, was recorded for all patients with 1-year imaging follow-up.

\section{Study Variables}

Study variables included the nominal dimensions (diameter, length) of both the manually determined and the computed PEDs. In cases in which a multi-PED construct was used, analysis was limited to the first implanted device.

\section{Study Design}

The Sim\&Size software became available in France and Switzerland for use in routine clinical practice at the end of 2016. For cases performed before the software had become available (all patients from center A), the presumed optimal device dimensions were manually determined on the basis of $2 \mathrm{D}$ measurements made on rotational angiography acquired before PED implantation by 1 of 2 local neurointerventionalists with considerable PED experience. The manually determined presumed optimal device was then implanted. In these cases, the computed optimal PED dimensions were retrospectively determined by virtual simulation by a team of Sim\&Size experts, which included software engineers and at least 1 local neurointerventionalist with considerable PED experience, all blinded to the operating neurointerventionalists' manual choice. For cases performed after Sim\&Size software had become available (all patients from center B), preimplantation virtual device simulation was routinely performed before implantation by a team of Sim\&Size experts that included software engineers and at least 1 local neurointerventionalist with considerable PED experience. In these cases, the manually determined presumed optimal device dimensions were retrospectively determined on the basis of $2 \mathrm{D}$ measurements made on rotational angiography acquired before PED implantation by 1 of 2 local neurointerventionalists with considerable PED experience who was blinded to the results of virtual simulation.

\section{Data Collection}

Clinical and radiographic baseline data as well as the manually determined presumed optimal and computed optimal PED dimensions were collected by the local teams in both participating centers. Anonymized data were then collected centrally and prepared for analysis at the Department of Radiology, Basel University Hospital, University of Basel, Basel, Switzerland.

\section{Statistical Analysis}

Descriptive statistics for a set of predefined variables of interest are provided (see study variables above). The degree of agreement between the manually determined presumed optimal and computed optimal device dimensions was evaluated with the Cohen $\kappa$. The Wilcoxon signed rank test was performed to analyze differences in nominal device length and nominal device diameter between sizing methods. Differences in baseline characteristics were evaluated with a Student $t$ test, Fisher exact test, and Wilcoxon signed rank test, as applicable. Statistical analysis was performed 


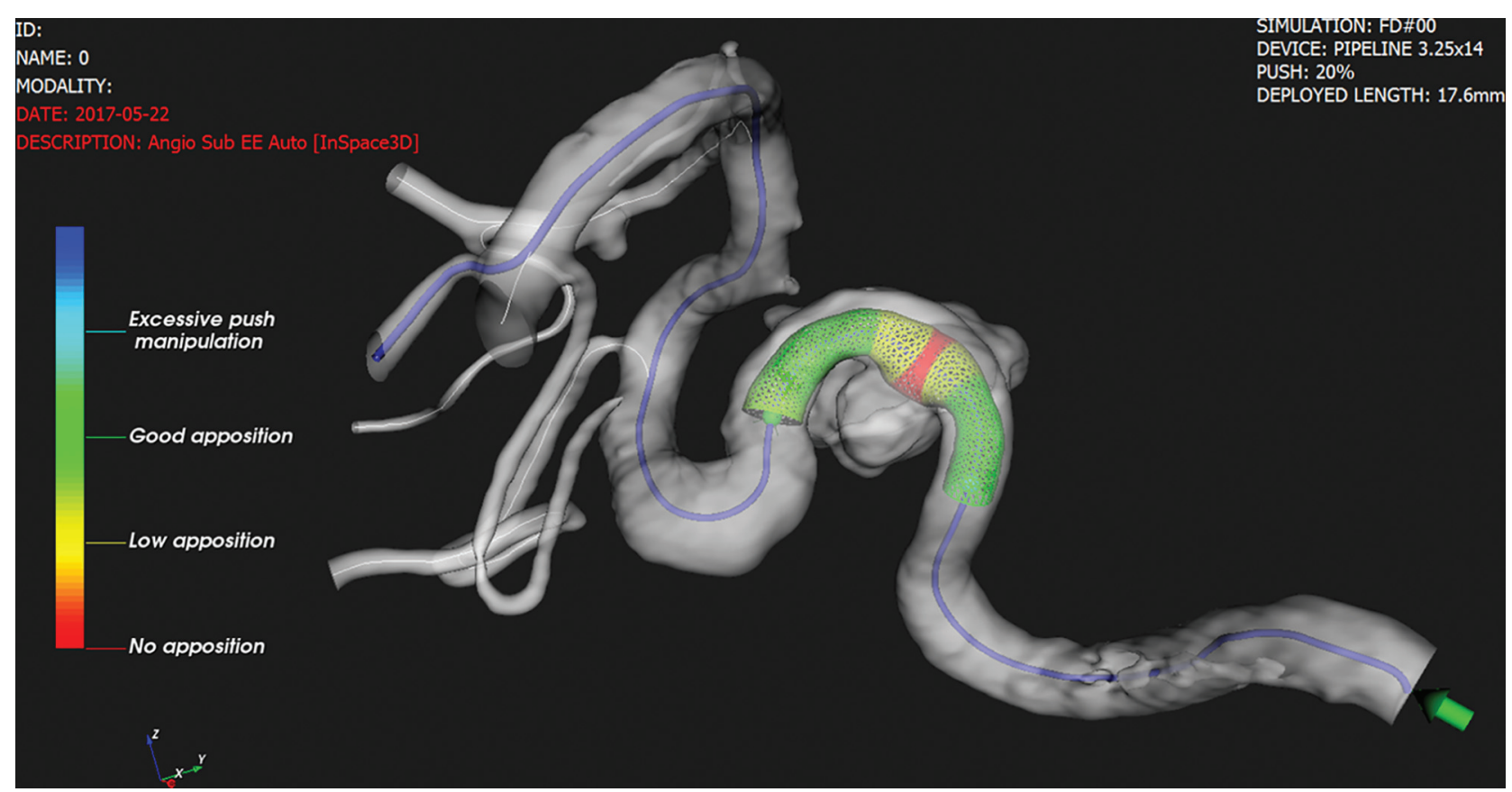

FIG 1. The Sim\&Size software anticipates intraluminal PED behavior, wall apposition, and device length after implantation on the basis of preimplantation rotational angiography DICOM data. The planned microcatheter trajectory for PED delivery is indicated in blue. Anticipated wall apposition along the covered segment is color-coded from red (no apposition) to green (good apposition). Courtesy of Cindy Wehrli and Phil Häfliger from Medtronic, Switzerland.

with SPSS (Version 22.0; IBM, Armonk, New York). Statistical significance was defined as $P<.05$.

\section{Software-Based Computation of PED Dimensions}

The commercially available Sim\&Size software is a fast simulation tool that predicts intravascular behavior of flow diverters such as the PED (Fig 1). ${ }^{17}$ On the basis of DSA DICOM data, the software reconstructs the $3 \mathrm{D}$ vessel geometry using volume-rendering. The accuracy of the reconstruction can be reviewed in real-time and, if necessary, optimized manually. Potential microcatheter trajectories in the target vessel are then computed on the basis of the vessel centerline. Once trajectory and device type have been selected, the desired distal and proximal landing zones are defined manually. A first proposal is provided instantly for device dimensions compatible with the chosen landing zones. Device deformation, porosity, and degree of wall apposition are simultaneously incorporated and displayed. Different landing zones, device diameters, lengths, and mechanical manipulations (eg, amount of push during PED deployment) can be virtually tested in real-time.

\section{RESULTS}

\section{Baseline Characteristics}

Seventy-four consecutive patients from 2 tertiary neurovascular centers were included. Center A contributed 63 patients (85.1\%), and center B contributed the remaining 11 patients (14.9\%). While the mean age distribution between the 2 centers was not different (overall: $58.6 \pm 13.3$ years; center A: $58.6 \pm 14.0$ years; center B: $58.5 \pm 8.6$ years), aneurysms in center A were significantly larger (overall: $8.8 \pm 7.2 \mathrm{~mm}$; center A: $9.3 \pm 7.7 \mathrm{~mm}$; center B: $6.3 \pm 2.9 \mathrm{~mm}, P<.05)$ and significantly more often extradural in location (overall: 52/74 cases [70.3\%]; center A:
Table 1: Baseline characteristics ${ }^{a}$

\begin{tabular}{lc}
\hline \multicolumn{1}{c}{ Characteristics } \\
\hline Sex (No.) (\%) \\
Male & $63(85.1 \%)$ \\
Female & $11(14.9 \%)$ \\
Patient age (mean) (SD, range) (yr) & $58.6(13.3,30-83)$ \\
Ruptured aneurysms (No.) (\%) & $5(6.8 \%)$ \\
Acute dissection (No.) (\%) & $15(20.3 \%)$ \\
Location of aneurysms (No.) (\%) & \\
Cervical ICA & $10(13.5 \%)$ \\
Petrous ICA & $13(17.6 \%)$ \\
Cavernous ICA & $26(35.1 \%)$ \\
Paraophthalmic ICA & $10(13.5 \%)$ \\
Communicating ICA & $1(1.4 \%)$ \\
Choroidal ICA & $1(1.4 \%)$ \\
Vertebrobasilar circulation & $3(4.1 \%)$ \\
ACA & $4(5.4 \%)$ \\
MCA & $6(8.1 \%)$ \\
Maximum aneurysm diameter (mean) & $8.8(7.2,2.0-40.0)$ \\
(SD, range) (mm) & \\
Multi-PED constructs (No.) (\%) & $7(9.5 \%)$ \\
Use of additional coils (No.) (\%) & $11(14.9 \%)$ \\
\hline
\end{tabular}

Note:-ACA indicates anterior cerebral artery.

${ }^{a}$ Location of ICA aneurysms is provided according to the New York University classification. ${ }^{35}$ Number of patients $=74$.

50/63 cases [79.4\%]; center B: $2 / 11$ cases [18.2\%], $P<.01$ ). Baseline characteristics are provided in Table 1.

\section{Treatment Characteristics, Perioperative Complications, and Outcome}

Coils were used in addition to the PED in 11 cases (14.9\%); and a multi-PED construct, in 7 cases $(9.5 \%)$. Periprocedural complications occurred in 11 patients (14.9\%), including PED deployment failure ( $n=5$ cases, $6.8 \%$ ), ischemia in the same territory as 

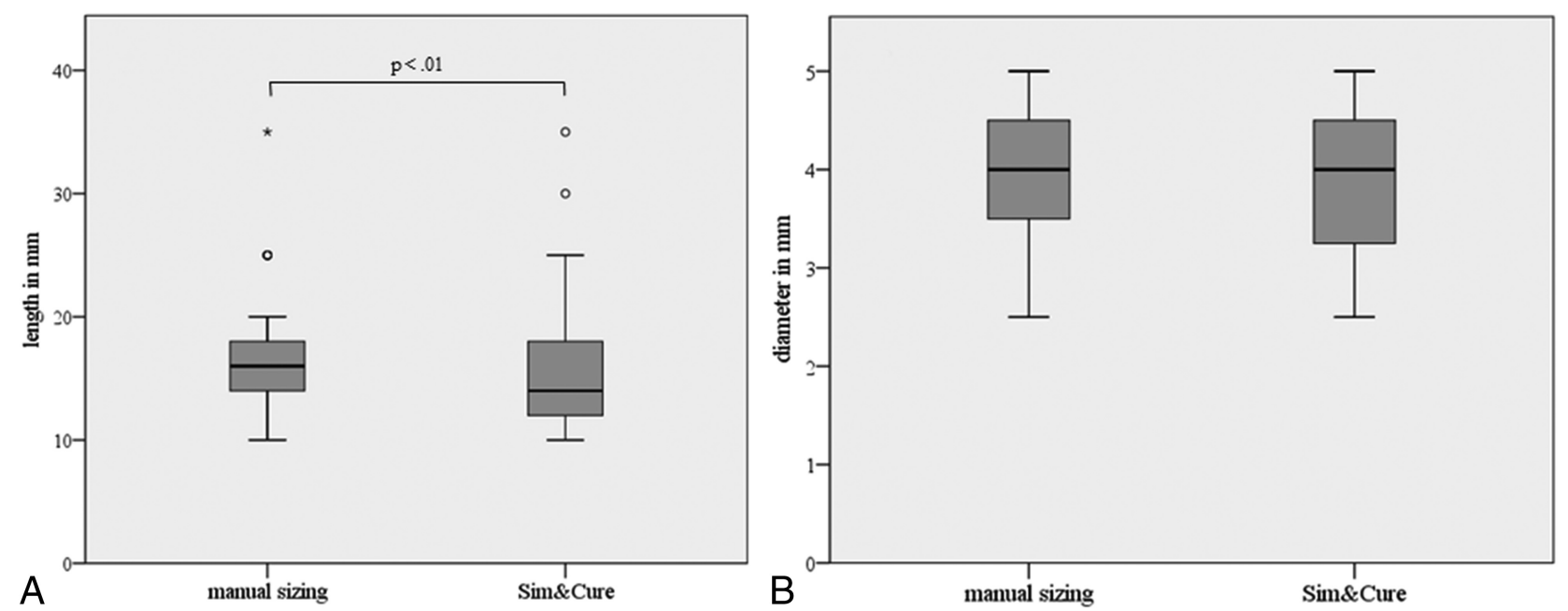

FIG 2. Boxplots illustrating differences between manually determined presumed optimal device dimensions and computed optimal PED dimensions for PED length $(A)$ and for PED diameter $(B)$.

PED deployment $(n=4,5.4 \%)$, and hemorrhage in the same territory as the PED deployment $(n=2,2.7 \%)$. One-year imaging follow-up was available for $47 / 74$ patients $(63.5 \%)$ and revealed residual aneurysm perfusion in 6 patients $(8.1 \%)$. Differences between the 2 participating centers in terms of perioperative complications and outcome were not statistically significant. Details are provided in On-line Table 1.

\section{Degree of Agreement}

Sim\&Size computation suggested different device dimensions than the manually determined presumed optimal dimensions in $67 / 74$ patients $(90.5 \%)$. Accordingly, the agreement index between neurointerventionalists and Sim\&Size was low $(\kappa$ for diameter $=0.219 ; \kappa$ for length $=0.149, P<.01$ ). Agreement remained low when the cohorts from each contributing center were analyzed separately (center A: $\kappa$ for diameter $=0.203$; $\kappa$ for length $=$ $0.129, P<.05$; center B: $\kappa$ for diameter $=0.294 ; \kappa$ for length $=$ $0.230, P<.05)$ and when patients who received a multi-PED construct were excluded from the analysis (overall: $\kappa$ for diameter $=0.239 ; \kappa$ for length $=0.125, P<.01$; center A: $\kappa$ for diameter $=0.222, \kappa$ for length $=0.119, P<.01$; center B: $\kappa$ for diameter $=0.349 ; \kappa$ for length $=0.186, P<.05)$.

\section{PED Dimensions}

The median length of software-based optimal PEDs was shorter than the median length of manually determined presumed optimal devices (14 versus $16 \mathrm{~mm}$ ) (Fig 2). This difference did reach statistical significance $(T=402, r=-0.28, P<.01)$ and remained significant when patients who received a multi-PED construct were excluded from analysis $(T=375, r=-0.24, P<.01)$. There was no significant difference with regard to the median PED diameter, which was $4 \mathrm{~mm}$ in both groups (Fig 2). Accordingly, the mean length of the computed optimal PEDs was shorter (15.22 versus $16.31 \mathrm{~mm}$ ), while the mean diameter was comparable in both groups (3.94 versus $3.89 \mathrm{~mm}$ ). Details are provided in Table 2.

The Sim\&Size software suggested a shorter nominal PED length than manually determined in $56.8 \%(n=42)$, the same
Table 2: Dimensions (diameter, length) of the manually determined presumed optimal and computed optimal PEDs

\begin{tabular}{lcc}
\hline & $\begin{array}{c}\text { Manually } \\
\text { Determined }\end{array}$ & $\begin{array}{c}\text { Computed } \\
\text { Optimal }\end{array}$ \\
\hline PED diameter (mm) & & \\
Mean (SD) & $3.89(0.70)$ & $3.94(0.69)$ \\
Range & $2.5-5$ & $2.5-5$ \\
Median (IQR) & $4(3.50-4.50)$ & $4(3.25-4.50)$ \\
PED length (mm) & & \\
Mean (SD) & $16.31(3.94)$ & $15.22(5.21)$ \\
Range & $10-35$ & $10-35$ \\
Median (IQR) & $16(14-18)$ & $14(11.5-18)$ \\
\hline
\end{tabular}

Note:- $-\mathrm{QQR}$ indicates interquartile range.

length in $25.7 \%(n=19)$, and a longer device length in the remaining $17.6 \%(n=13)$ of cases (Fig 3$)$. The proportion of cases in which the software proposed a shorter length was higher for intradural compared with extradural aneurysms and was the highest for more distal aneurysms arising from areas such as the anterior or middle cerebral artery. However, the length differences between software-based optimal PEDs and manually determined presumed optimal devices was smaller (most, $0-4 \mathrm{~mm}$ ) for intracranial aneurysms compared with their extradural counterparts (Fig 4).

\section{DISCUSSION}

We analyzed a multicenter cohort of 74 patients undergoing treatment with PEDs for intracranial aneurysms (Table 1) and found low agreement between the neurointerventionalists' manual device selection and the computed optimal PED dimensions determined by a team of Sim\&Size experts blinded to the neurointerventionalist's manual-sizing decision. While we believe that this low agreement ultimately reflects the potential for optimization of the device-sizing process, it should not be interpreted per se as proof that virtual simulation performs better than conventional manual selection.

We found that the computed optimal PEDs were significantly shorter (Table 2 and Fig 2), which we attribute to the ability of the software to reliably anticipate implanted length and consequently 
accurate landing zones, thereby allowing confident selection of the shortest possible device. Accordingly, the proportion of cases in which the Sim\&Size software suggested a shorter device was higher for intradural aneurysms where side-branches and perforators come into play (Fig 4). Even though the true consequences

Differences between manually determined and computed optimal PED dimensions

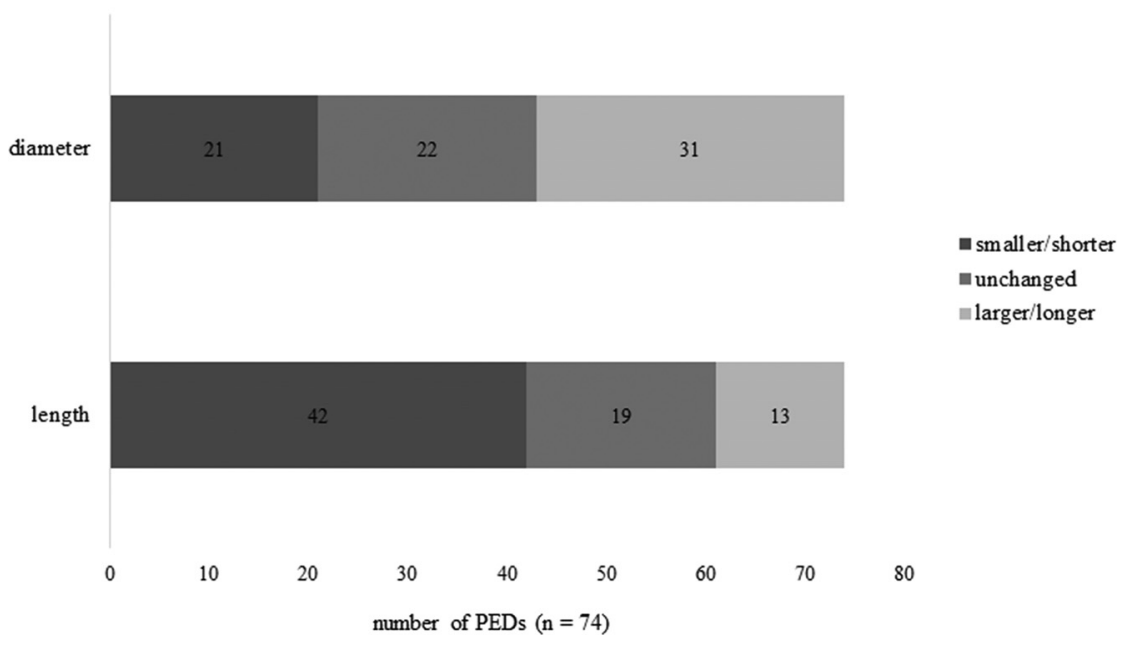

FIG 3. Bar graph illustrating differences between manually determined presumed optimal device dimensions and computed optimal PEDs. Computed optimal device diameter was larger in 31 cases, identical to the neurointerventionalists' manual selection in 22 cases, and smaller in the remaining 21 cases. Computed optimal device length was shorter in 42 cases, identical to the neurointerventionalists' manual selection in 19 cases, and longer in the remaining 13 cases. of this device-length reduction remain to be clarified in dedicated further research, it is intuitive that particularly for intradural aneurysms, the minimal amount of endoprosthetic material required to achieve a goal is desirable, as is the potential to remove uncertainties related to unexpected landing zones and, consequently, unpredictable wall apposition or unanticipated branch vessel coverage. ${ }^{18-21}$ There were also cases in which virtual simulation suggested a longer device or where suggestion of a larger diameter led to an increase in length of the implanted PED (Fig 3). These, at times, very sizeable discrepancies between manually selected and computed optimal device dimensions typically occurred in large, dysplastic, or fusiform aneurysms of the extradural ICA, as well as in aneurysms associated with dissection (On-line Tables 1-3).

Notwithstanding the fact that the diameter difference did not reach statistical significance, we think that the Sim\&Size algorithm suggested the smallest diameter necessary to maintain wall apposition along the entire length of the device, which, in theory, would reduce the risk for oversizing and, thereby, promote device efficacy (Table 2 and Fig 2). ${ }^{15,22,23}$ Nevertheless, there were cases in which
90

80

70

60

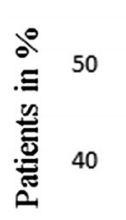

30

20

10

0

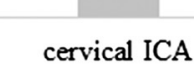

$\mathrm{n}=5 / 10$
Shorter length suggested by Sim\&Cure 
virtual simulation suggested a larger device or where suggestion of a longer device required increasing the nominal diameter of the PED (Fig 3). One may speculate that these are cases in which manual device selection would have resulted in inadvertent undersizing or insufficient device length, with the potential consequence of known periprocedural complications such as device migration or endoleak formation. ${ }^{24}$ Alternatively, as in 1 example from our series, a cervical ICA dissection (patient 27, On-line Table 1) was initially covered using a single PED of $4 \mathrm{~mm}$ in diameter and $18 \mathrm{~mm}$ in length, as chosen from manual measurements. Virtual simulation, however, revealed that a device of 30 $\mathrm{mm}$ in nominal length would be required to optimally cover the entire dissection, which, in turn, would require using a device of 5 $\mathrm{mm}$ in nominal diameter to maintain wall apposition at the proximal end. In summary, our study was neither designed nor powered to assess the clinical or radiologic consequences of device length or diameter modifications; thus, the true benefits of preimplantation virtual simulation remain hypothetic until proved in a prospectively conducted and, ideally, randomized trial.

Computer-based planning tools that virtually visualize stent length in situ have been described. ${ }^{25-29}$ Previous work has revealed, for instance, how virtual simulation reduces the error in length prediction compared with the nominal length provided by the manufacturers. ${ }^{30,31}$ Much of this research in the field of virtual device simulation has focused, however, on technical aspects of accurate modeling and prediction of intraluminal device behavior, with only a very few small case series of in vivo use of simulation tools in the field of neurointervention. ${ }^{32}$ Moreover, previous software solutions generally remain of limited use with regard to their application in a real-world setting, given the constraints such as a lack of information regarding wall apposition and the inability to test, in real-time, multiple device dimensions and positions. Altogether, the present study is, to our knowledge, the first attempt to objectify the impact of preimplantation PED simulation in a real-world setting, and our results, therefore, represent an important step toward translation of this novel technology into routine clinical practice.

Our study has several limitations, and we recommend caution when interpreting the results. First, the 2 participating centers did not contribute an equal number of patients, and their aneurysm population differed significantly in terms of location and size. We, therefore, performed an exploratory subgroup analysis to clarify the particular aneurysm categories that were most affected by simulation. Second, the average number of devices used per aneurysm in the Pipeline for the Intracranial Treatment of Aneurysms ${ }^{33}$ and Pipeline for Uncoilable or Failed Aneurysms ${ }^{34}$ trials was 1.52 and 3.1, respectively. We were obliged to limit our analysis to the first implanted device, given that the Sim\&Size algorithm is restricted to simulation of a single device at this time. Third, the purpose of the present study was only to evaluate whether the use of a computer-based simulation model results in the selection of different PED dimensions, and we certainly acknowledge a lack of study design and statistical power for any meaningful outcome analysis. The significance of selecting PEDs of different dimensions in terms of long-term outcome remains, therefore, to be clarified in dedicated future research. Finally, our results are based on a small number of practitioners and patients, meaning that further studies on larger cohorts will be necessary to confirm our results.

\section{CONCLUSIONS}

Experience with PEDs remains characterized by heterogeneity in device sizing and deployment technique. Furthermore, the properties of the PED require not only appropriate but optimal device dimensions to achieve treatment success and minimize complications. It is therefore appealing to facilitate device sizing and positioning through preimplantation virtual simulation techniques. We found, in the present study, robust evidence that preimplantation simulation with the Sim\&Size software results in selection of different PED dimensions compared with conventional manual device sizing, and preimplantation device simulation led, in particular, to a measurable decrease in median device length. We believe that the benefits of the Sim\&Size software may, therefore, be the greatest for intradural aneurysms, where side branches and perforators are relevant. In summary, we are confident that our findings reveal the potential of the software for optimization of the device-selection process, even if the impact on outcome remains to be clarified in dedicated research.

\section{ACKNOWLEDGMENTS}

We thank Piergiorgio Canci, Application Engineer at Sim\&Cure, and Christophe Chnafa, Research and Development engineer at Sim\&Cure, who provided us with data; Cindy Wehrli and Phil Häfliger from Medtronic, Switzerland, for providing us with Fig 1 and with their Sim\&Size expertise; and Dr Selina Ackermann from the University Hospital Basel for editorial assistance.

Disclosures: Vincent Costalat—RELATED: Stock/Stock Options: Sim\&Cure.

\section{REFERENCES}

1. Turjman F, Acevedo G, Moll T, et al. Treatment of experimental carotid aneurysms by endoprosthesis implantation: preliminary report. Neurol Res 1993;15:181-84 CrossRef Medline

2. Geremia G, Haklin M, Brennecke L. Embolization of experimentally created aneurysms with intravascular stent devices. AJNR Am J Neuroradiol 1994;15:1223-31 Medline

3. Fiorella D, Kelly ME, Albuquerque FC, et al. Curative reconstruction of a giant midbasilar trunk aneurysm with the Pipeline embolization device. Neurosurgery 2009;64:212-17; discussion 217 CrossRef Medline

4. Fiorella D, Lylyk P, Szikora I, et al. Curative cerebrovascular reconstruction with the Pipeline embolization device: the emergence of definitive endovascular therapy for intracranial aneurysms. $\mathrm{J} \mathrm{Neu}$ rointerv Surg 2009;1:56-65 CrossRef Medline

5. Lylyk P, Miranda C, Ceratto R, et al. Curative endovascular reconstruction of cerebral aneurysms with the Pipeline embolization device: the Buenos Aires experience. Neurosurgery 2009;64:632-42; discussion 642-43; quiz N6 CrossRef Medline

6. ADMINISTRATION U.S. FOOD AND DRUG. Premarket Approval (PMA). 2011; https://www.accessdata.fda.gov/scripts/cdrh/cfdocs/ cfpma/pma.cfm?ID=P100018. Accessed August 8, 2018

7. Patel PD, Chalouhi N, Atallah E, et al. Off-label uses of the Pipeline embolization device: a review of the literature. Neurosurg Focus 2017;42:E4 CrossRef Medline

8. Dabus G, Grossberg JA, Cawley CM, et al. Treatment of complex anterior cerebral artery aneurysms with Pipeline flow diversion: mid-term results. J Neurointerv Surg 2017;9:147-51 CrossRef Medline

9. Fischer S, Perez MA, Kurre W, et al. Pipeline embolization device for the treatment of intra- and extracranial fusiform and dissecting 
aneurysms: initial experience and long-term follow-up. Neurosurgery 2014;75:364-74; discussion 374 CrossRef Medline

10. Kulcsar Z, Wetzel SG, Augsburger L, et al. Effect of flow diversion treatment on very small ruptured aneurysms. Neurosurgery 2010;67: 789-93 CrossRef Medline

11. Phillips TJ, Wenderoth JD, Phatouros CC, et al. Safety of the Pipeline embolization device in treatment of posterior circulation aneurysms. AJNR Am J Neuroradiol 2012;33:1225-31 CrossRef Medline

12. Zhang $Y$, Huang QH, Fang $Y$, et al. A novel flow diverter (Tubridge) for the treatment of recurrent aneurysms: a single-center experience. Korean J Radiol 2017;18:852-59 CrossRef Medline

13. Rajah G, Narayanan S, Rangel-Castilla L. Update on flow diverters for the endovascular management of cerebral aneurysms. Neurosurg Focus 2017;42:E2 CrossRef Medline

14. Shapiro M, Raz E, Becske T, et al. Building multidevice Pipeline constructs of favorable metal coverage: a practical guide. $A J N R A m J$ Neuroradiol 2014;35:1556-61 CrossRef Medline

15. Shapiro M, Raz E, Becske T, et al. Variable porosity of the Pipeline embolization device in straight and curved vessels: a guide for optimal deployment strategy. AJNR Am J Neuroradiol 2014;35:727-33 CrossRef Medline

16. Brinjikji W, Murad MH, Lanzino G, et al. Endovascular treatment of intracranial aneurysms with flow diverters: a meta-analysis. Stroke 2013;44:442-47 CrossRef Medline

17. Sim\&Cure RdlV, 34790 Grabels, France. https://sim-and-cure.com/ product. Accessed August, 29, 2018

18. Kulcsár Z, Ernemann U, Wetzel SG, et al. High-profile flow diverter (Silk) implantation in the basilar artery: efficacy in the treatment of aneurysms and the role of the perforators. Stroke 2010;41:1690-96 CrossRef Medline

19. van Rooij WJ, Sluzewski M. Perforator infarction after placement of a Pipeline flow-diverting stent for an unruptured A1 aneurysm. AJNR Am J Neuroradiol 2010;31:E43-44 CrossRef Medline

20. Potts MB, Shapiro M, Zumofen DW, et al. Parent vessel occlusion after Pipeline embolization of cerebral aneurysms of the anterior circulation. J Neurosurg 2017;127:1333-41 CrossRef Medline

21. Raz E, Shapiro M, Becske T, et al. Anterior choroidal artery patency and clinical follow-up after coverage with the Pipeline embolization device. AJNR Am J Neuroradiol 2015;36:937-42 CrossRef Medline

22. Makoyeva A, Bing F, Darsaut TE, et al. The varying porosity of braided self-expanding stents and flow diverters: an experimental study. AJNR Am J Neuroradiol 2013;34:596-602 CrossRef Medline

23. Mut F, Cebral JR. Effects of flow-diverting device oversizing on hemodynamics alteration in cerebral aneurysms. AJNR Am J Neuroradiol 2012;33:2010-16 CrossRef Medline
24. Zhou G, Su M, Yin YL, et al. Complications associated with the use of flow-diverting devices for cerebral aneurysms: a systematic review and meta-analysis. Neurosurg Focus 2017;42:E17 CrossRef Medline

25. Bernardini A, Larrabide I, Petrini L, et al. Deployment of self-expandable stents in aneurysmatic cerebral vessels: comparison of different computational approaches for interventional planning. Comput Methods Biomech Biomed Engin 2012;15:303-11 CrossRef Medline

26. Kim JH, Kang TJ, Yu WR. Mechanical modeling of self-expandable stent fabricated using braiding technology. J Biomech 2008;41: 3202-12 CrossRef Medline

27. Ma D, Dargush GF, Natarajan SK, et al. Computer modeling of deployment and mechanical expansion of neurovascular flow diverter in patient-specific intracranial aneurysms. J Biomech 2012; 45:2256-63 CrossRef Medline

28. Ma D, Dumont TM, Kosukegawa $H$, et al. High-fidelity virtual stenting (HiFiVS) for intracranial aneurysm flow diversion: in vitro and in silico. Ann Biomed Eng 2013;41:2143-56 CrossRef Medline

29. Bouillot $P$, Brina $O$, Yilmaz H, et al. Virtual-versus-real implantation of flow diverters: clinical potential and influence of vascular geometry. AJNR Am J Neuroradiol 2016;37:2079-86 CrossRef Medline

30. Fernandez H, Macho JM, Blasco J, et al. Computation of the change in length of a braided device when deployed in realistic vessel models. Int J Comput Assist Radiol Surg 2015;10:1659-65 CrossRef Medline

31. Narata AP, Blasco J, Roman LS, et al. Early results in flow diverter sizing by computational simulation: quantification of size change and simulation error assessment. Oper Neurosurg (Hagerstown) 2018;15:557-66 CrossRef Medline

32. Martinez-Galdamez M, Holtmannspöetter M, Isokangas $M$, et al. Simulation in clinical practice: first experience with Sim\&Size before implantation of flow diverter (Pipeline) or WEB-device for the treatment of intracranial aneurysms. In: Proceedings of the Anatomy Biology Clinical Correlations-Working group in Interventional Neuroradiology Seminar, Val d'Isère, France. January 15-20, 2017

33. Nelson PK, Lylyk P, Szikora I, et al. The Pipeline embolization device for the intracranial treatment of aneurysms trial. AJNR Am J Neuroradiol 2011;32:34-40 CrossRef Medline

34. Becske T, Kallmes DF, Saatci I, et al. Pipeline for uncoilable or failed aneurysms: results from a multicenter clinical trial. Radiology 2013; 267:858-68 CrossRef Medline

35. Shapiro M, Becske T, Riina HA, et al. Toward an endovascular internal carotid artery classification system. AJNR Am J Neuroradiol 2014;35:230-36 CrossRef Medline 